\title{
Correction to: Spontaneous intracranial hypotension: key features for a frequently misdiagnosed disorder
}

\section{Carlos Perez-Vega $^{1}$ • Pilar Robles-Lomelin ${ }^{1}$ - Isabel Robles-Lomelin ${ }^{1}$ • Victor Garcia Navarro ${ }^{1,2,3}$}

Published online: 28 May 2021

(C) Fondazione Società Italiana di Neurologia 2021

Correction to: Neurological Sciences (2020) 41:2433-2441 https://doi.org/10.1007/s10072-020-04368-8

The above article was published with error. The caption for Figure 4 should be replaced with the following text.

Fig. 4 T1-weighted sagittal head MRI of a patient with SIH before (a) and after (b) treatment. Note the difference in the mamillopontine distance ( $\mathrm{I}: \mathrm{a}=5.3 \mathrm{~mm}, \mathrm{~b}=7.09 \mathrm{~mm}$ ), suprasellar cistern (II: $a=0.41 \mathrm{~mm}, b=7.38 \mathrm{~mm}$ ), and prepontine cistern (III: $\mathrm{a}=4.06 \mathrm{~mm}, \mathrm{~b}=5.19 \mathrm{~mm}$ )

Publisher's note Springer Nature remains neutral with regard to jurisdictional claims in published maps and institutional affiliations.

The online version of the original article can be found at https://doi.org/ 10.1007/s10072-020-04368-8

Victor Garcia Navarro garcianavarrov@tec.mx

1 School of Medicine and Health Sciences, Tecnologico de Monterrey, Campus Guadalajara, Zapopan, Mexico

2 Instituto Neurológico de Guadalajara S.C, Guadalajara, Jalisco, Mexico

3 Hospital Puerta de Hierro Andares, Guadalajara, Jalisco, Mexico 